\title{
Achieving Efficient Polymer Solar Cells Based on Near-Infrared Absorptive Backbone Twisted Non-fullerene Acceptors Through a Synergistic Strategy of Indacenodiselenophene Fused-ring Core and Chlorinated Terminal Group
}

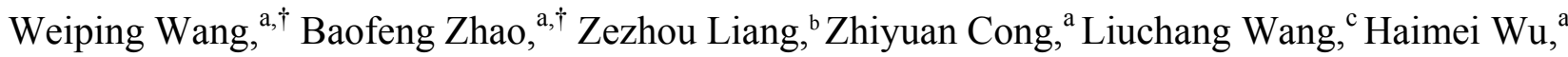
Nan Zheng, d, ${ }^{\text {,* }}$ Chao Gao ${ }^{\mathrm{a}, *}$

${ }^{a}$ Xi' an Key Laboratory of Liquid Crystal and Organic Photovoltaic Materials, State Key Laboratory of Fluorine \& Nitrogen Chemicals, Xi'an Modern Chemistry Research Institute, Xi'an, Shaanxi, 710065, P. R. China. E-Mail: chaogao1974@hotmail.com (C. Gao).

${ }^{\mathrm{b}}$ Key Laboratory of Physical Electronics and Devices of the Ministry of Education \& Shaanxi Key Lab of Photonic Technique for Information, School of Electronic Science and Engineering, Faculty of Electronic and Information Engineering, Xi'an Jiaotong University, Xi'an, Shaanxi 710049, P. R. China.

${ }^{\mathrm{c}}$ School of Chemical Engineering, Xi'an University, No. 168 of South Taibai Road, Xi'an, 10065, China.

${ }^{\mathrm{d}}$ Institute of Polymer Optoelectronic Materials and Devices, State Key Laboratory of Luminescent Materials and Devices, South China University of Technology, Guangzhou, 510640, P. R. China. E-Mail: zhengn@ scut.edu.cn.

\footnotetext{
${ }^{\dagger} \mathrm{W}$. Wang and B. Zhao contributed equally to this work.
} 


\section{Content of the supporting information}

\begin{tabular}{|l|c|}
\hline Content & Page \\
\hline Material synthesis and characterization. & $\mathrm{S} 3-5$ \\
\hline Measurement & $\mathrm{S} 5$ \\
\hline Fabrication and characterization of the photovoltaic cells & $\mathrm{S} 5-6$ \\
\hline Carrier mobility measurement. & $\mathrm{S} 6$ \\
\hline GIXD Characterization. & $\mathrm{S} 6$ \\
\hline $\begin{array}{l}\text { Figure S1-S8. }{ }^{1} \mathrm{H} \text { NMR } \text { and }{ }^{13} \text { C NMR spectra of the M1, i-IDSe, i-IDSe-4F, and } \\
\text { i-IDSe-4Cl. }\end{array}$ & $\mathrm{S} 7-10$ \\
\hline Figure S9. Thermalgravimetric analysis curves of i-IDSe, i-IDSe-4F, and i-IDSe-4Cl. & $\mathrm{S} 11$ \\
\hline Figure S10. CV plot of PBDB-T film. & $\mathrm{S} 11$ \\
\hline Figure S11. ${ }^{1 / 2}$ vs V plots of the three devices. & $\mathrm{S} 12$ \\
\hline Figure S12. TEM pictures with 100 nm and 50 nm scale bars. & $\mathrm{S} 13$ \\
\hline $\begin{array}{l}\text { Figure S13-16. Transient absorption characteristics of PBDB-T, i-IDSe, } \\
\text { i-IDSe-4F, and i-IDSe-4Cl film. }\end{array}$ & $\mathrm{S} 13-14$ \\
\hline $\begin{array}{l}\text { Table S1. Calculations of total energy and their geometries of i-IDSe, i-IDSe-4F, and } \\
\text { i-IDSe-4Cl. }\end{array}$ & $\mathrm{S} 15-16$ \\
\hline $\begin{array}{l}\text { Table S2. Calculated molecular energy levels of i-IDSe, i-IDSe-4F, and i-IDSe-4Cl at } \\
\text { their optimized geometry. }\end{array}$ & $\mathrm{S} 16-17$ \\
\hline Table S3. Measurement of the hole and electron mobilities. & $\mathrm{S} 17$ \\
\hline References & $\mathrm{S} 17$ \\
\hline
\end{tabular}




\section{Material synthesis and characterization.}

PBDB-T was synthesized in our laboratory according to the literature. ${ }^{1}$ Using gel permeation chromatography (GPC) method on a PLGPC220 instrument at $150{ }^{\circ} \mathrm{C}$ with 1,2,4-trichlorobenzene as eluent and polystyrene as standard, the weight-average molecular weight $\left(\mathrm{M}_{\mathrm{w}}\right)$ of PBDB-T is measured as $62 \mathrm{kDa}$ with a polydispersity index (PDI) of 2.81. All the other chemicals were purchased as reagent grade from Aladdin, J \& K, and Alfa Aesar Chemical Co., and used without further purification unless otherwise noted. The indacenodiselenophene tin-derivative $^{2}$ (compound 1) was synthesized according to the literature. The key intermediate 5-bromo-4-(2-ethylhexyloxy)-thiophene-3-carbaldehyde ${ }^{3}$ (compound 2) was synthesized according to the published literature.
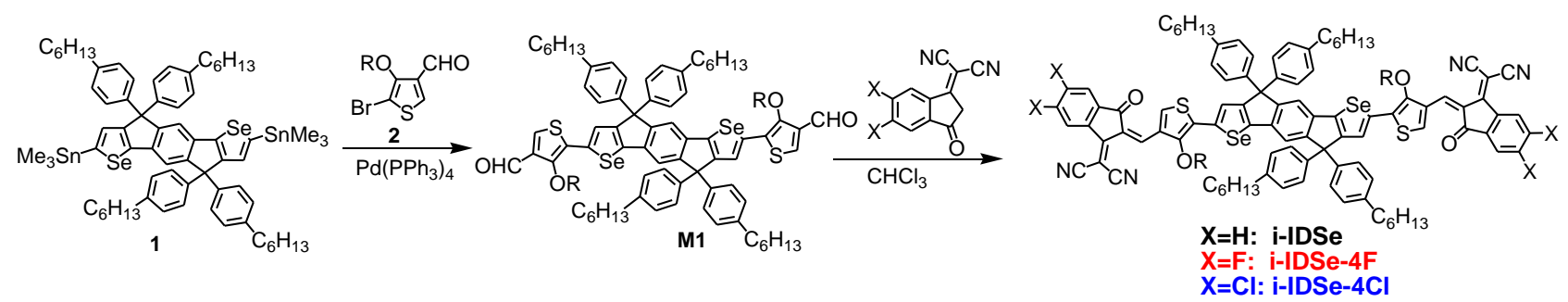

Scheme S1. Synthetic route of i-IDSe, i-IDSe-4F, and i-IDSe-4Cl. Reagents and conditions: a) $\mathrm{Pd}\left(\mathrm{PPh}_{3}\right)_{4}$, toluene, reflux; b) pyridine, $\mathrm{CHCl}_{3}$

Synthesis of compound M1.

Compound 1 (2.27 g, 1.7mmol) and 5-bromo-4-(2-ethylhexyloxy)- thiophene-3-carbaldehyde (compound 2) (1.53 $\mathrm{g}, 4.8 \mathrm{mmol}$ ) were dissolved in a $250 \mathrm{~mL}$ dry flask in degassed toluene $(75 \mathrm{~mL})$, the mixture was flushed with nitrogen for $30 \mathrm{~min}$, then $\left(\mathrm{Pd}\left(\mathrm{PPh}_{3}\right)_{4}\right)(120 \mathrm{mg})$ was added under nitrogen. After stirring the mixture at $90{ }^{\circ} \mathrm{C}$ overnight, the reaction was quenched with $50 \mathrm{~mL}$ water and extracted with ethyl acetate. Then, the combined organic solvent was washed with brine and dried over anhydrous magnesium sulfate. After removing the solvent, the compound M1 was purified with column chromatography on silica-gel using mixture of ethyl acetate (EA) and hexane (1: 15 by volume) as an yellow solid by yield $65.1 \% .{ }^{1} \mathrm{H}$ NMR (500 MHz, $\mathrm{CDCl}_{3}$ ), $\delta(\mathrm{ppm}): 9.93$ (s, 2H), $7.39(\mathrm{~d}, 4 \mathrm{H}), 7.15(\mathrm{~d}, 8 \mathrm{H}), 7.10(\mathrm{~d}, 8 \mathrm{H}), 6.86(\mathrm{~s}, 2 \mathrm{H}), 4.05(\mathrm{~d}, 4 \mathrm{H}), 2.57(\mathrm{t}, 8 \mathrm{H}), 1.77(\mathrm{~m}, 2 \mathrm{H}), 1.62-1.56(\mathrm{~m}$, 8H), 1.49-1.41(m, 8H), 1.34-1.27(m, 32H), 0.96-0.86 (m, 24H). ${ }^{13} \mathrm{C}$ NMR (125 MHz, $\left.\mathrm{CDCl}_{3}\right), \delta(\mathrm{ppm}): 180.26$, $164.68,158.66,153.24,148.62,146.17,143.19,141.92,141.00,137.82,128.53,127.85,124.15,119.57,117.91$, $111.54,74.51,64.35,39.54,35.59,31.73,31.35,30.43,29.17,29.05,23.84,22.98,22.60,14.10,14.06,11.15$.

Synthesis of i-IDSe.

To a mixture of M1 (350 mg, $0.23 \mathrm{mmol}$ ) and 2-(3-oxo-2,3-dihydro- $1 H$-inden-1-ylidene)malononitrile (230 mg, $1.18 \mathrm{mmol})$ were dissolved in a dry flask in $25 \mathrm{~mL}$ chloroform, pyridine $(0.5 \mathrm{~mL})$ was added at room temperature. 
Then the mixture was vigorously stirred at $65{ }^{\circ} \mathrm{C}$ for $3 \mathrm{~h}$. After cooling down, the mixture was extracted with chloroform. Then, the organic layer was dried over anhydrous magnesium sulfate and concentrated to afford the crude product. The crude product solution was poured into methanol and filtered through a Buchner funnel. Then the solid product of compound i-IDSe was purified by silica gel by using chloroform as eluent to give a black solid (150 mg). ${ }^{1} \mathrm{H}$ NMR (500 MHz, $\mathrm{CDCl}_{3}$ ), $\delta 9.14(\mathrm{~s}, 2 \mathrm{H}), 8.63(\mathrm{dd}, 2 \mathrm{H}), 7.83(\mathrm{t}, 2 \mathrm{H}), 7.66(\mathrm{~m}, 6 \mathrm{H}), 7.44(\mathrm{~s}, 2 \mathrm{H})$, 7.19(d, 8H), 7.13 (d, 8H), 6.83 (s, 2H ), $4.16(\mathrm{~m}, 4 \mathrm{H}), 2.61$ (t, 8H), 1.90 (m, 2H), 1.63-1.54 (m, 16H), 1.36-1.28 (m, 32H), 0.98-0.86 (m, 24H). ${ }^{13} \mathrm{C}$ NMR (125 MHz, $\left.\mathrm{CDCl}_{3}\right), \delta 189.07,169.18,160.78,159.85,154.82,153.97$, $148.66,143.42,142.10,140.67,140.14,138.27,136.76,134.48,133.63,132.75,128.65,127.90,125.89,124.91$, $123.11,118.28,118.20,117.62,115.52,114.96,109.84,75.71,67.05,64.41,39.36,35.60,31.71,31.31,30.08$, 29.13, 28.99, 23.52, 22.99, 22.57, 14.06, 10.93. Anal.Calcd for $\left(\mathrm{C}_{114} \mathrm{H}_{118} \mathrm{~N}_{4} \mathrm{O}_{4} \mathrm{~S}_{2} \mathrm{Se}_{2}\right)$ : C 74.81, H 6.50; Found: C 74.49, H 6.45 .

Synthesis of i-IDSe-4F.

To a mixture of $\mathbf{M 1}(480 \mathrm{mg}, 0.32 \mathrm{mmol})$ and 2-(5,6-difluoro-3-oxo-2,3-dihydro-1H-inden-1ylidene)malononitrile $(368 \mathrm{mg}, 1.6 \mathrm{mmol})$ were dissolved in a dry flask in $30 \mathrm{~mL}$ chloroform, pyridine $(0.5 \mathrm{~mL})$ was added at room temperature. Then the mixture was vigorously stirred at $65{ }^{\circ} \mathrm{C}$ for $3 \mathrm{~h}$. After cooling down, the mixture was extracted with chloroform. Then, the organic layer was dried over anhydrous magnesium sulfate and concentrated to afford the crude product. The crude product solution was poured into methanol and filtered through a Buchner funnel. Then the solid product of compound i-IDSe-4F was purified by silica gel by using chloroform as eluent to give a black solid (190 mg, 67.2\%). ${ }^{1} \mathrm{H}$ NMR (500 MHz, $\left.\mathrm{CDCl}_{3}\right), \delta 9.12$ (s, 2H), 8.51 (dd, 2H), 7.67(s, 2H), $7.61(\mathrm{t}, 2 \mathrm{H}), 7.45(\mathrm{~s}, 2 \mathrm{H}), 7.18(\mathrm{~d}, 8 \mathrm{H}), 7.13(\mathrm{~d}, 8 \mathrm{H}), 6.83(\mathrm{~s}, 2 \mathrm{H}), 4.16(\mathrm{~m}, 4 \mathrm{H}), 2.60(\mathrm{t}, 8 \mathrm{H})$, $1.91(\mathrm{~m}, 2 \mathrm{H}), 1.61-1.53(\mathrm{~m}, 16 \mathrm{H}), 1.37-1.29(\mathrm{~m}, 32 \mathrm{H}), 0.97-0.86(\mathrm{~m}, 24 \mathrm{H}) .{ }^{13} \mathrm{C}$ NMR $\left(125 \mathrm{MHz}, \mathrm{CDCl}_{3}\right), \delta 186.68$, $169.88,160.00,158.64,155.98,154.07,152.99,149.35,143.29,142.20,140.56,138.33,136.68,132.80,128.69$, $127.88,126.30,118.41,117.66,117.22,115.15,114.79,114.62,114.57,112.13,112.00,111.97,109.78,75.84$, $67.38,64.39,39.32,35.61,31.74,31.37,30.03,29.15,28.98,23.47,23.01,22.61,14.12,10.94$. Anal.Calcd for $\left(\mathrm{C}_{114} \mathrm{H}_{114} \mathrm{~F}_{4} \mathrm{~N}_{4} \mathrm{O}_{4} \mathrm{~S}_{2} \mathrm{Se}_{2}\right)$ : C 71.98, H 6.04; Found: C 71.90, H 6.06.

Synthesis of i-IDSe-4Cl.

To a mixture of $\mathbf{M 1}$ (280 $\mathrm{mg}, \quad 0.19 \mathrm{mmol})$ and 2-(5,6-dichloro-3-oxo-2,3-dihydro-1H-inden-1ylidene)malononitrile $(250 \mathrm{mg}, 0.95 \mathrm{mmol})$ were dissolved in a dry flask in $20 \mathrm{~mL}$ chloroform, pyridine $(0.4 \mathrm{~mL})$ was added at room temperature. Then the mixture was vigorously stirred at $65^{\circ} \mathrm{C}$ for $3 \mathrm{~h}$. After cooling down, the mixture was extracted with chloroform. Then, the organic layer was dried over anhydrous magnesium sulfate and 
concentrated to afford the crude product. The crude product solution was poured into methanol and filtered through a Buchner funnel. Then the solid product of compound i-IDSe-4CI was purified by silica gel by using chloroform as eluent to give a black solid (110 mg). ${ }^{1} \mathrm{H}$ NMR $\left(500 \mathrm{MHz}, \mathrm{CDCl}_{3}\right), \delta 9.12(\mathrm{~s}, 2 \mathrm{H}), 8.69(\mathrm{~s}, 2 \mathrm{H})$, 7.84(s, 2H), $7.68(\mathrm{~s}, 2 \mathrm{H}), 7.46(\mathrm{~s}, 2 \mathrm{H}), 7.19(\mathrm{~d}, 8 \mathrm{H}), 7.13(\mathrm{~d}, 8 \mathrm{H}), 6.82(\mathrm{~s}, 2 \mathrm{H}), 4.16(\mathrm{~m}, 4 \mathrm{H}), 2.61(\mathrm{t}, 8 \mathrm{H}), 1.90(\mathrm{~m}$, $2 \mathrm{H}), 1.63-1.53(\mathrm{~m}, 16 \mathrm{H}), 1.37-1.28(\mathrm{~m}, 32 \mathrm{H}), 0.97-0.86(\mathrm{~m}, 24 \mathrm{H}) .{ }^{13} \mathrm{C} \mathrm{NMR}\left(125 \mathrm{MHz}, \mathrm{CDCl}_{3}\right), \delta 186.65,170.03$, $160.10,158.46,156.42,154.15,149.59,142.19,140.53,138.87,138.85,135.99,133.23,128.68,127.88,126.61$, 124.56, 118.44, 118.16, 117.22, 115.10, 114.61, 109.70, 75.98, 67.43, 64.43, 39.33, 35.59, 31.71, 31.30, 30.04, 29.12, 28.97, 23.49, 22.97, 22.57, 14.05, 10.90. Anal.Calcd for $\left(\mathrm{C}_{114} \mathrm{H}_{114} \mathrm{Cl}_{4} \mathrm{~N}_{4} \mathrm{O}_{4} \mathrm{~S}_{2} \mathrm{Se}_{2}\right): \mathrm{C}$ 69.57, H. 5.84; Found: C 69.31, H 5.80.

\section{Measurement}

All the compounds were characterized by nuclear magnetic resonance spectra (NMR) in chloroform- $d\left(\mathrm{CDCl}_{3}\right)$ using tetramethylsilane (TMS) as the internal reference recorded on a Bruker AV 500 spectrometer at room temperature. The absorption spectra of the materials were measured by a PerkinElmer Lambda 750 UV/Vis/NIR spectrometer. Thermal stabilities of the acceptors were investigated on a Universal V2.6D TA instruments. The electrochemical cyclic voltammetry of the materials was conducted on a CHI 660D Electrochemical Workstation in a $0.1 \mathrm{~mol} / \mathrm{L}$ tetrabutylammonium hexafluorophosphate $\left(\mathrm{Bu}_{4} \mathrm{NPF}_{6}\right)$ acetonitrile solution, using glassy carbon, platinum wire, and $\mathrm{Ag} / \mathrm{Ag}^{+}$electrode as working electrode, the counter electrode, and the reference electrode, respectively. Atomic force microscopy (AFM) images were collected under ambient conditions in air on a MultiMode scanning probe microscope (AFM, Veeco Multi Mode V).

\section{Fabrication and characterization of the photovoltaic cells}

The device structure was ITO/ZnO/PBDB-T:acceptors/ $\mathrm{MoO}_{3} / \mathrm{Al}$. The carefully cleaned ITO glass was treated with ultraviolet-ozone for $20 \mathrm{~min}$. Zinc acetate dihydrate dissolved in 2-methoxyethanol and a small amount of ethanolamine was spin-cast on ITO glass, and then baked at $170{ }^{\circ} \mathrm{C}$ for $10 \mathrm{~min}$ in air to form a $40 \mathrm{~nm} \mathrm{ZnO} \mathrm{layer.}$ The photoactive layer $(80-90 \mathrm{~nm})$ was prepared by spin-coating from the chlorobenzene $(\mathrm{CB})$ solution of the NF acceptor and PBDB-T on the top of ITO/ZnO substrate in a glove box. Then a $10 \mathrm{~nm} \mathrm{MoO}$ layer and $120 \mathrm{~nm} \mathrm{Al}$ layer were deposited subsequently in a vacuum evaporator. As determined by the shadow mask used during deposition of $\mathrm{Al}$ cathode, the effective area of the device was $0.16 \mathrm{~cm}^{2}$. PCE values were determined on a Keithley 2400 source meter from current density $(J)$-voltage $(V)$ curve measurements under 1 sun, AM 1.5G spectrum from a monocrystal silicon cell (VLSI Standards Inc.) calibrated solar simulator (Newport model 94021A, $100 \mathrm{~mW} \mathrm{~cm}{ }^{-2}$ ). EQE was obtained by Solar Cell Spectral Response Measurement System QE-R3018 
(Enli Technology Co., Ltd.) and standard Si photovoltaic cell was employed to calibrate the light intensity.

\section{Carrier mobility measurement.}

To measure the hole and electron mobility, space-charge limited current (SCLC) method was used in a devices structure of ITO/PEDOT:PSS (40nm)/Active layer/ $\mathrm{MoO}_{3}(10 \mathrm{~nm}) / \mathrm{Ag}(100 \mathrm{~nm})$ and ITO/ZnO(40nm) /Active layer/Ca $(10 \mathrm{~nm}) / \mathrm{Al}(100 \mathrm{~nm})$ with the effective area of $0.16 \mathrm{~cm}^{2}$, respectively, by taking the dark current density and fitting the results to a space charge limited form. SCLC is described by the equation: ${ }^{4} J=9 \varepsilon_{0} \varepsilon_{n} \mu_{0} V^{2} / 8 L^{3}$, where $J$ is the current density, $\varepsilon_{0}$ is the permittivity of free space $\left(8.85 \times 10^{-12} \mathrm{~F} \mathrm{~m}^{-1}\right), \varepsilon_{r}$ is the relative dielectric constant of the transport medium, $\mu_{0}$ is the hole or electron mobility, $V\left(=V_{\text {appl- }} V_{\mathrm{bi}}\right)$ is the internal voltage in the device, where $V_{\text {appl }}$ is the applied voltage to the device and $V_{\mathrm{bi}}$ is the built-in voltage due to the relative work function difference of the two electrodes, $L$ is the film thickness of the active layer.

\section{GIXD Characterization}

GIXD measurements were performed on Xeuss 2.0. Samples were prepared on Si substrates using identical blend solutions as those used in devices. The liquid metal X-ray source radiates a beam with the wavelength of 1.34144 $\mathrm{nm}$ was incident at a grazing angle of $0.2^{\circ}$, selected to maximize the scattering intensity from the samples. The scattered X-ray signals were detected using a Dectris Pilatus 1M photon counting detector with the distance of $218.308 \mathrm{~mm}$. 


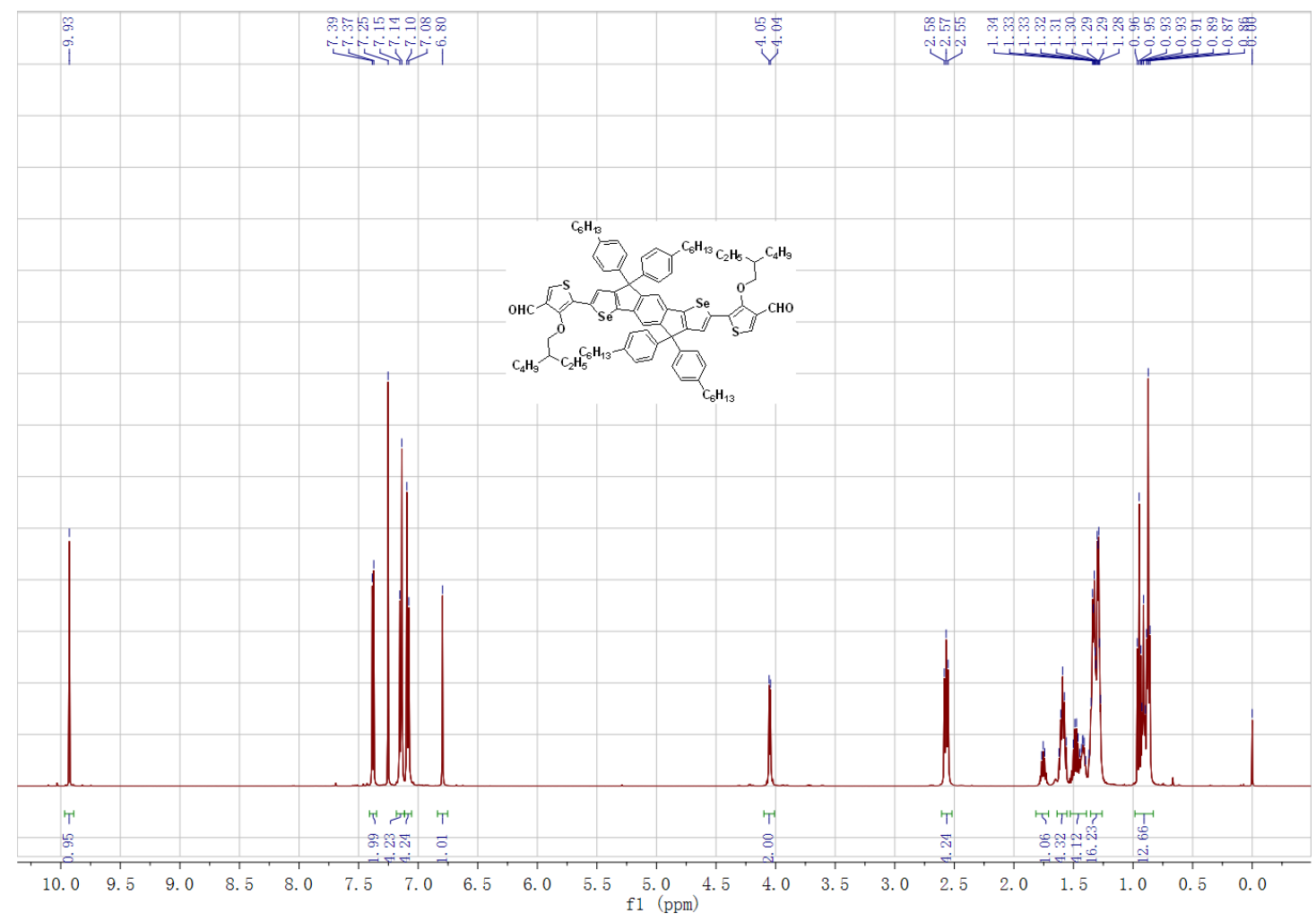

Figure S1. ${ }^{1} \mathrm{H}$ NMR spectrum of M1.

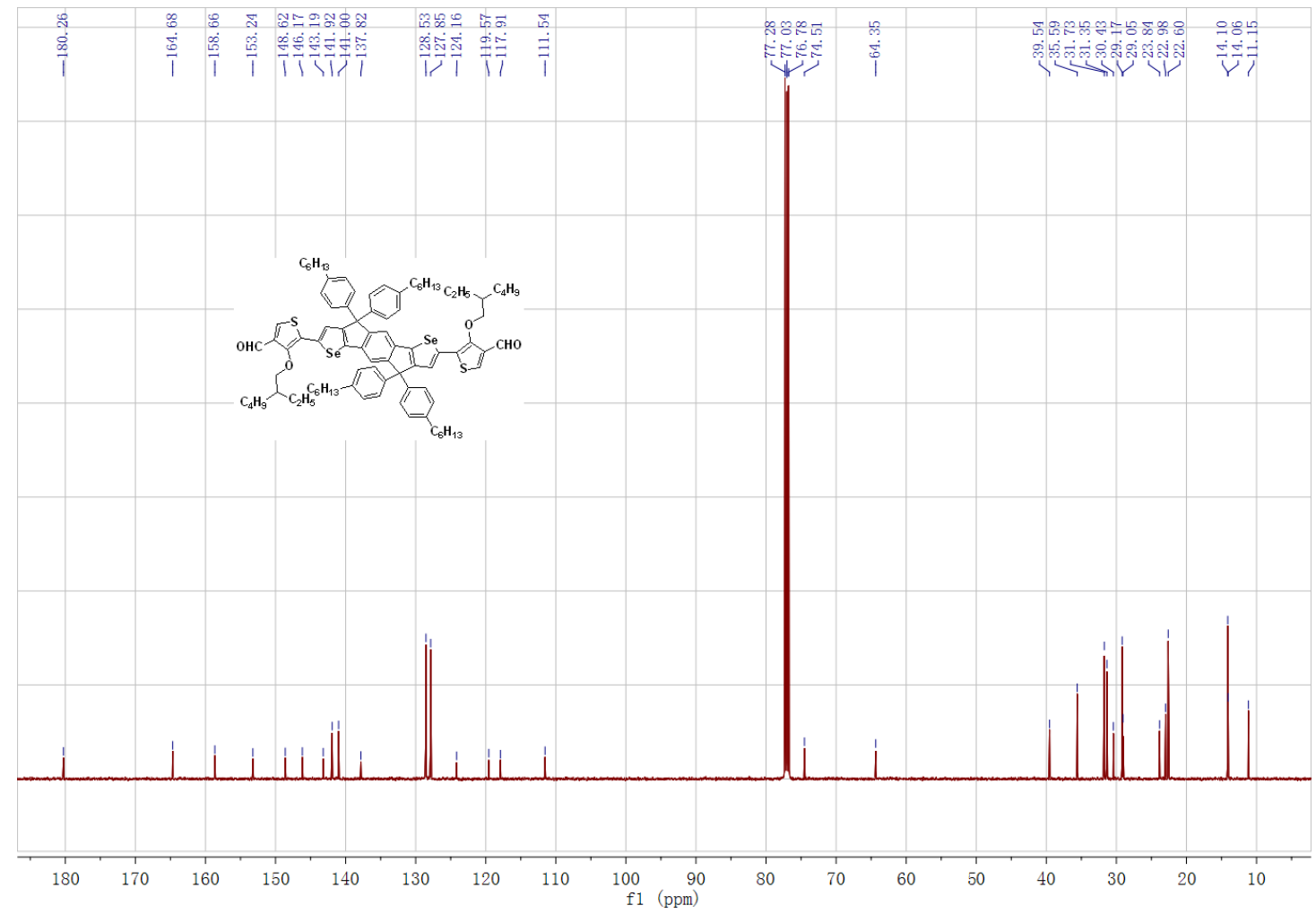

Figure S2. ${ }^{13} \mathrm{C}$ NMR spectrum of M1. 


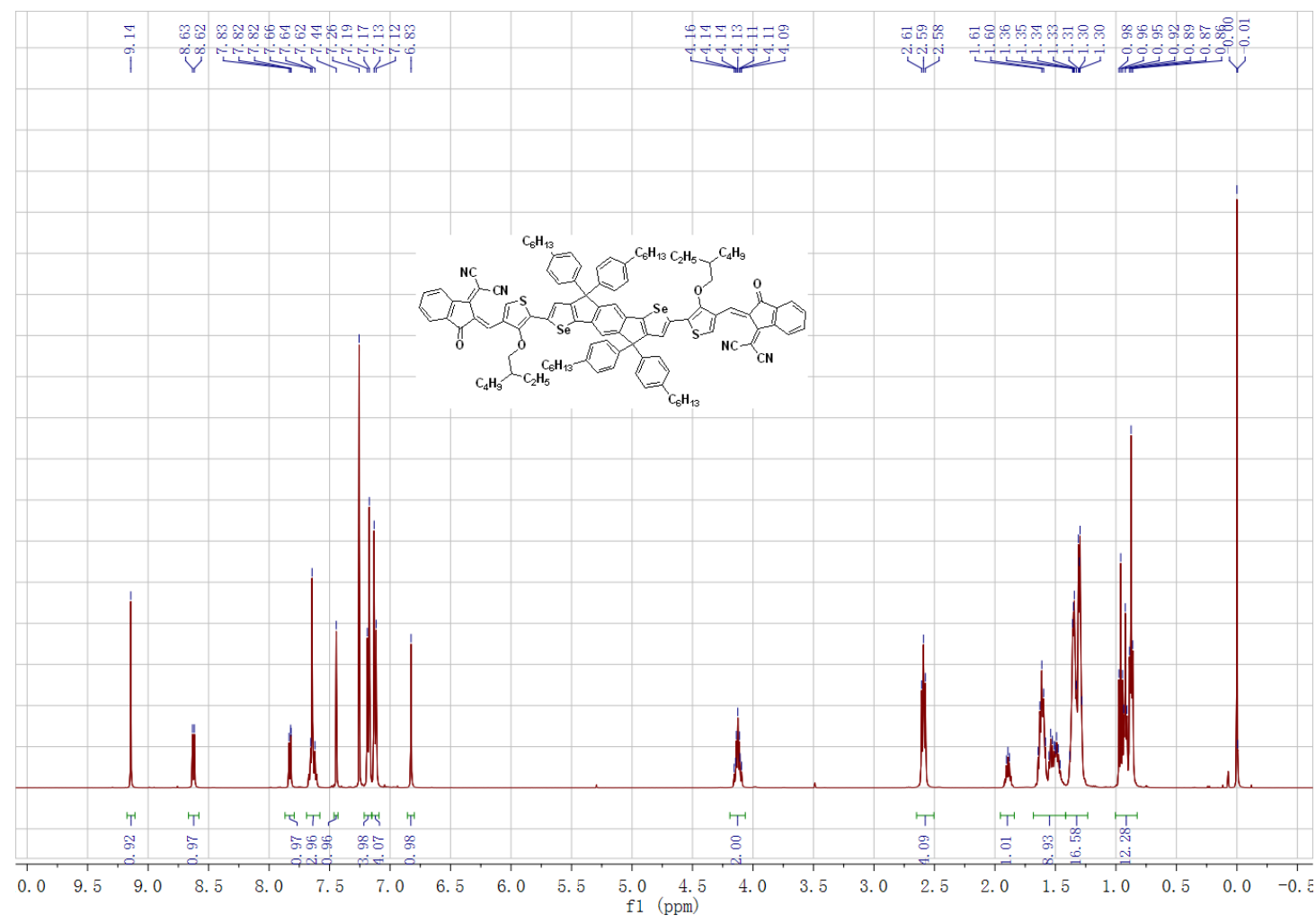

Figure S3. ${ }^{1} \mathrm{H}$ NMR spectrum of i-IDSe.

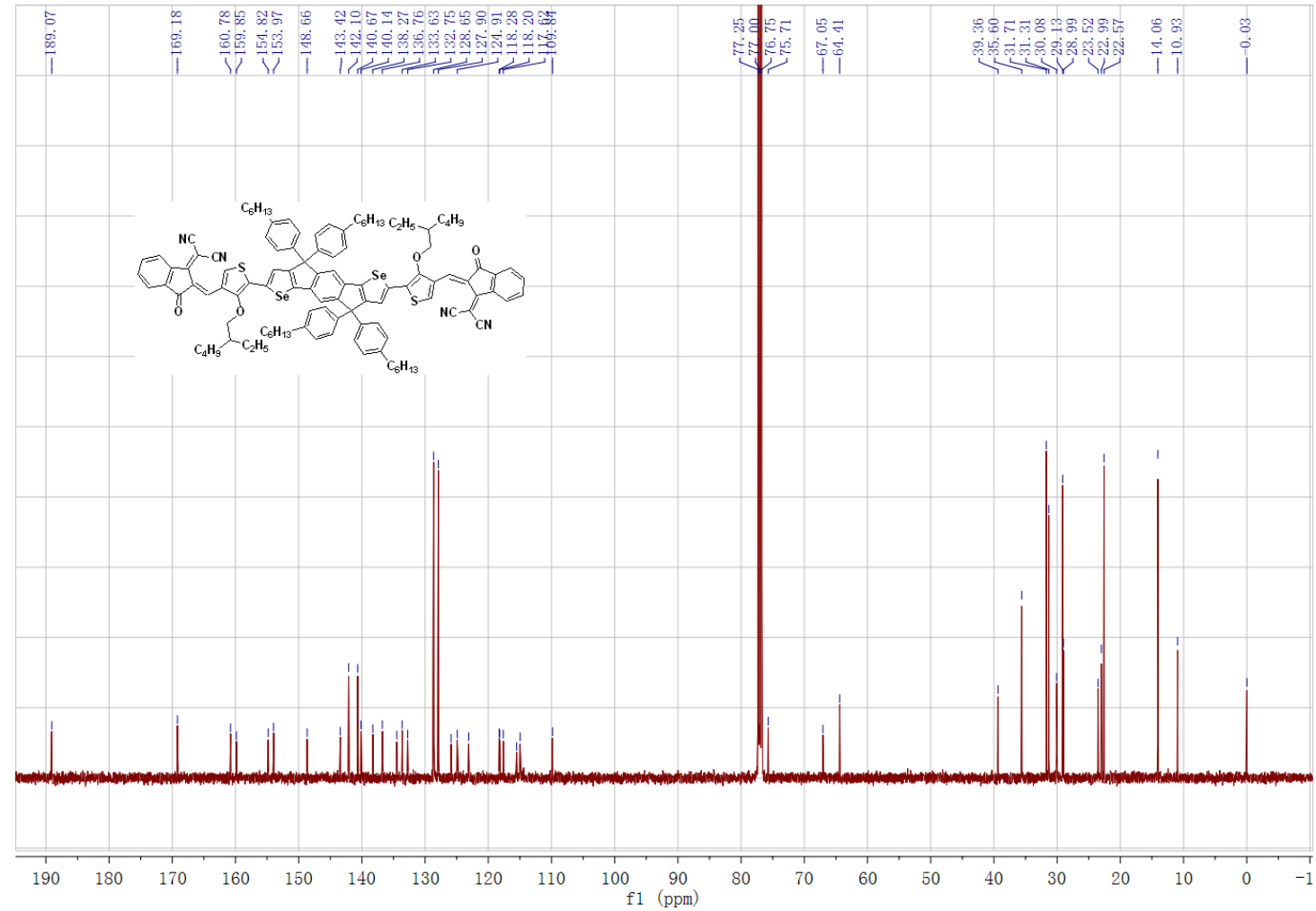

Figure S4. ${ }^{13} \mathrm{C}$ NMR spectrum of i-IDSe. 


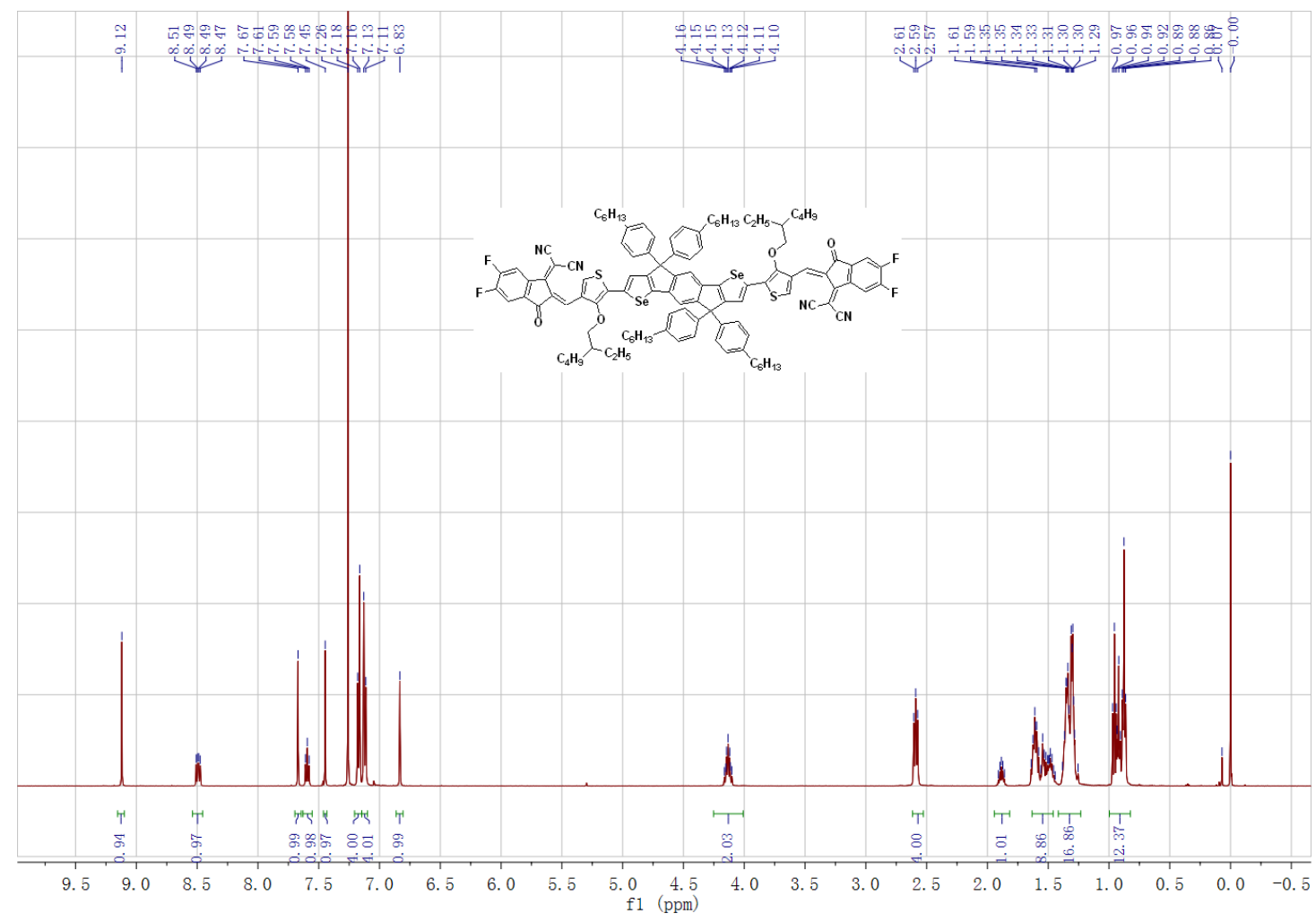

Figure S5. ${ }^{1}$ H NMR spectrum of i-IDSe-4F.

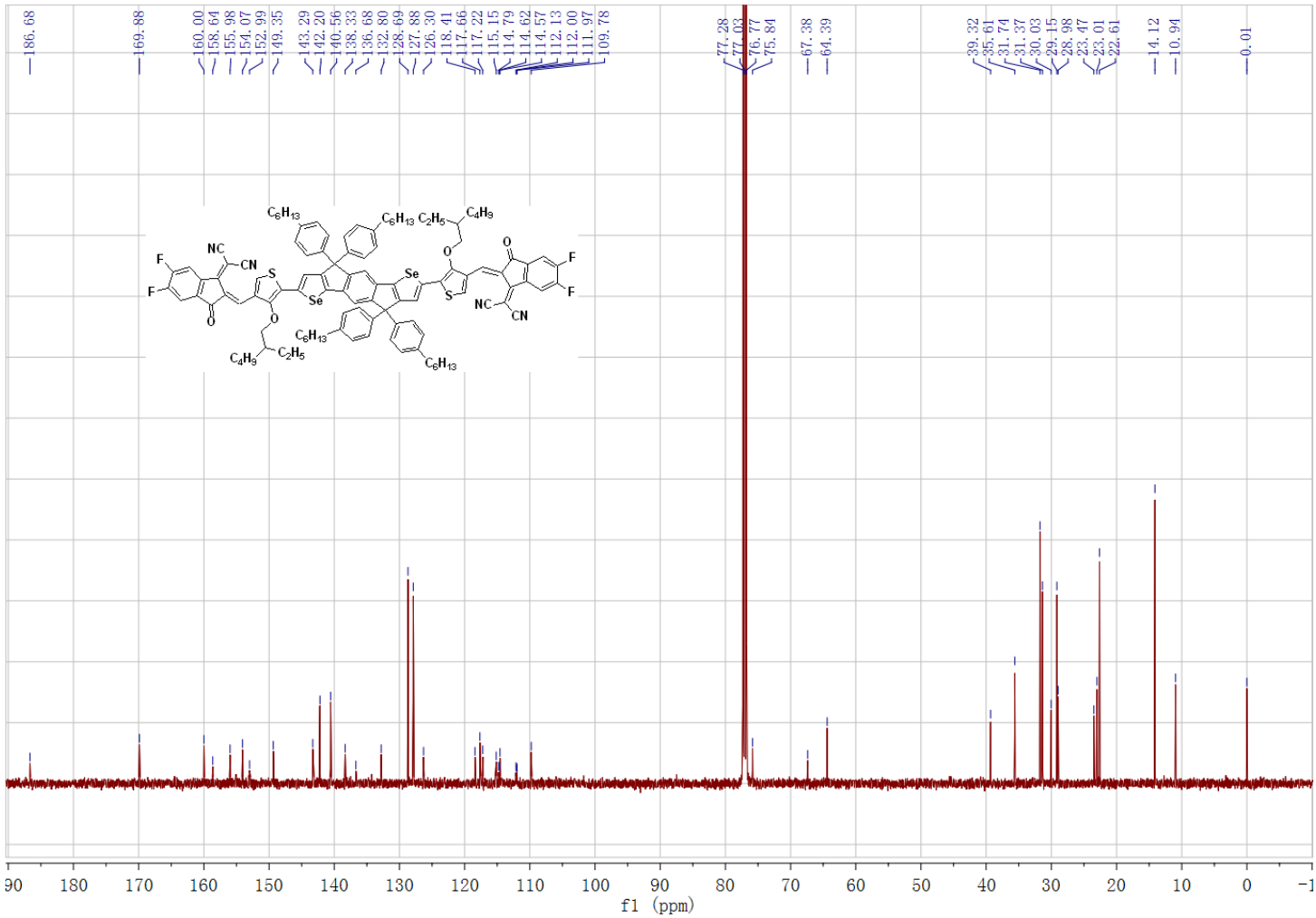

Figure S6. ${ }^{13} \mathrm{C}$ NMR spectrum of i-IDSe-4F. 


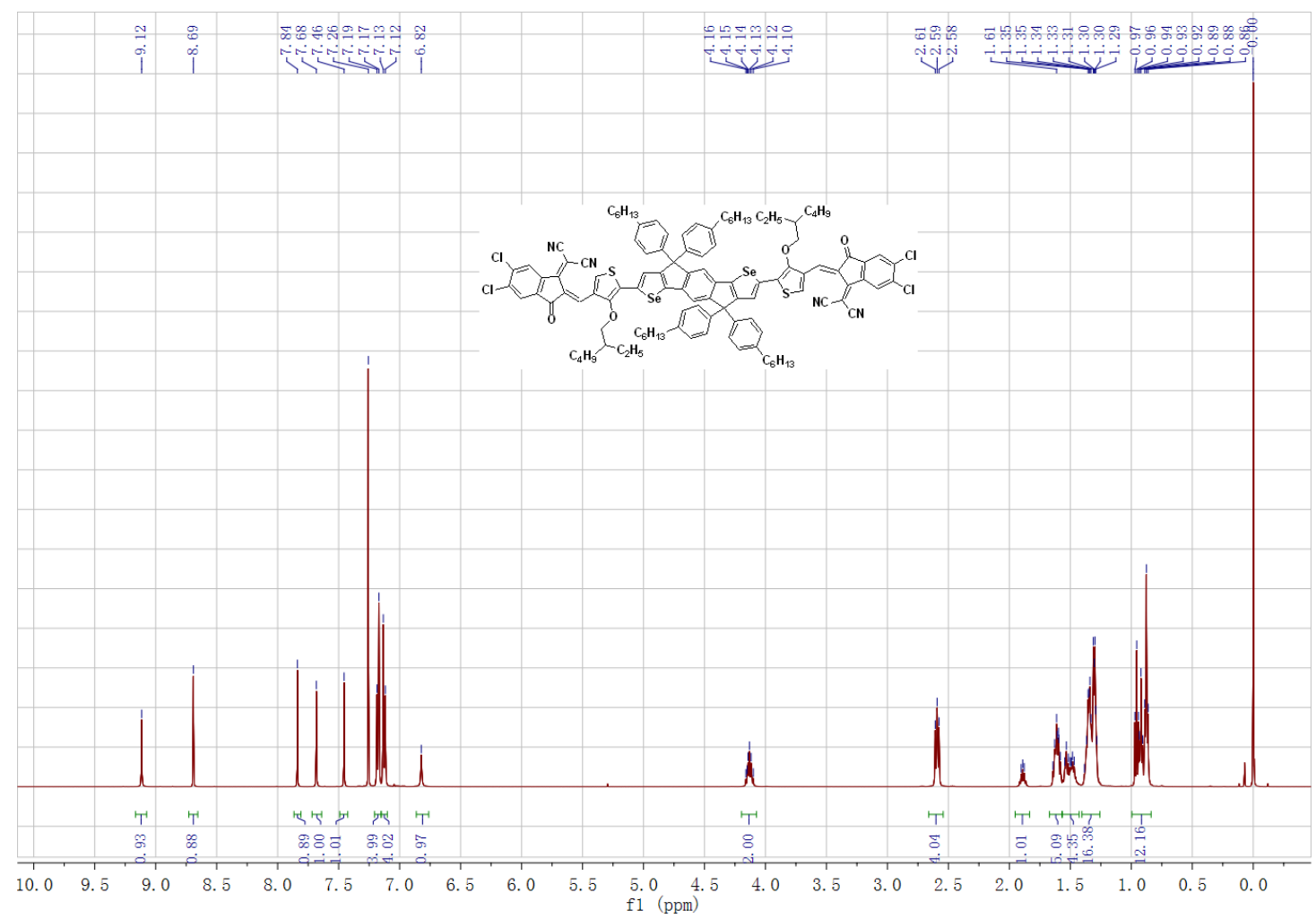

Figure S7. ${ }^{1} \mathrm{H}$ NMR spectrum of i-IDSe-4Cl.

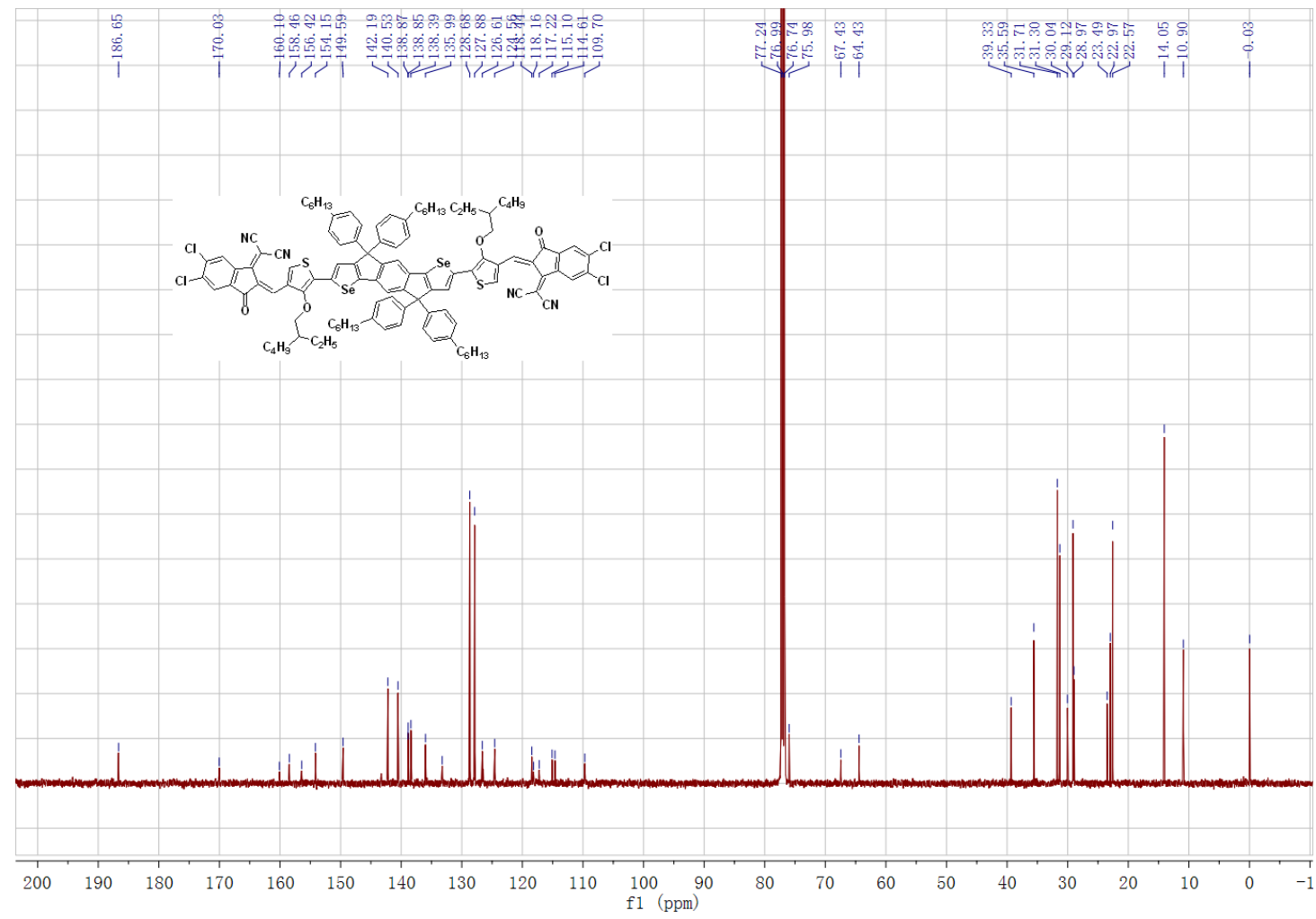

Figure S8. ${ }^{1}$ C NMR spectrum of i-IDSe-4Cl. 

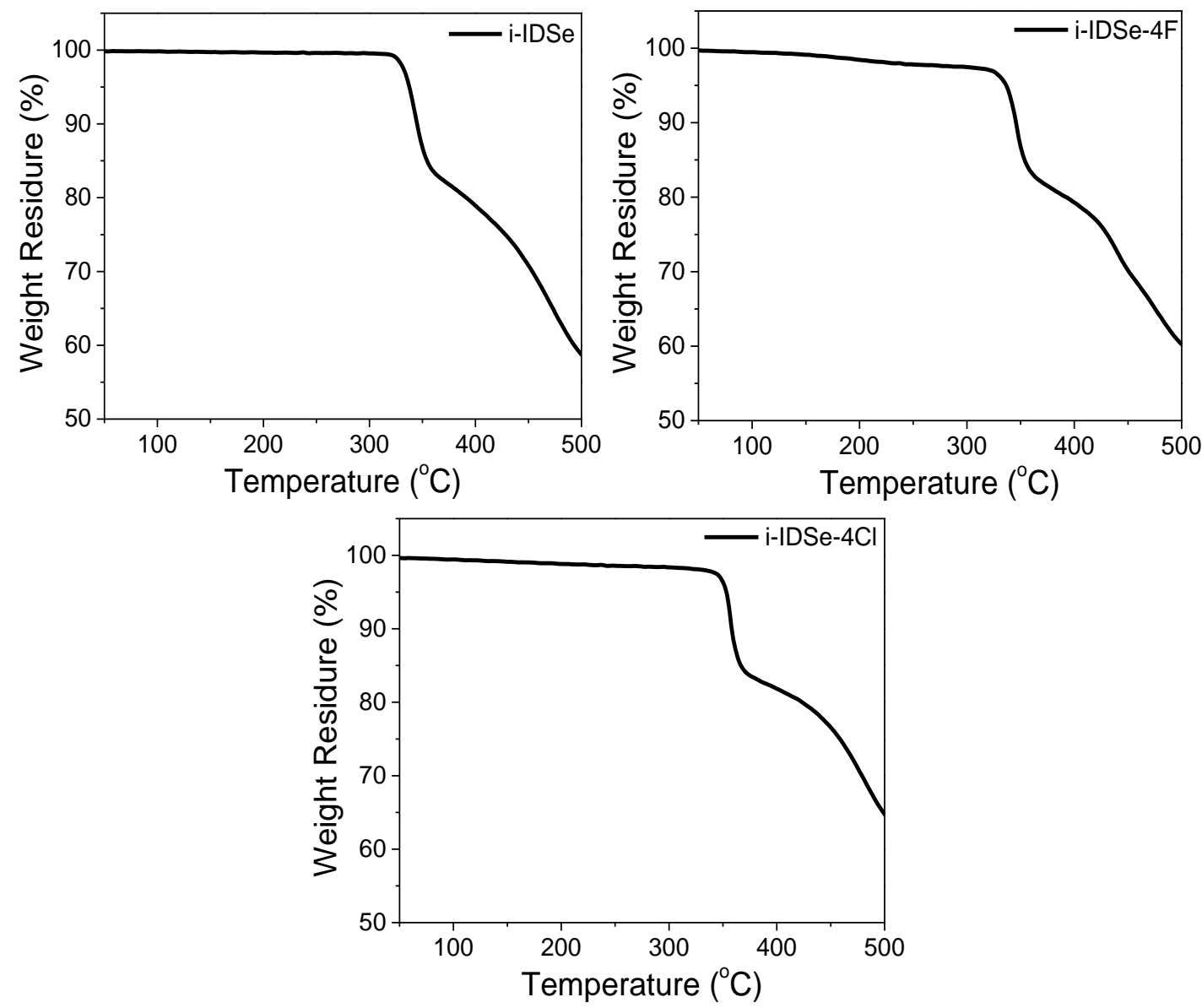

Figure S9. TGA plots of i-IDSe, i-IDSe-4F, and i-IDSe-4Cl.

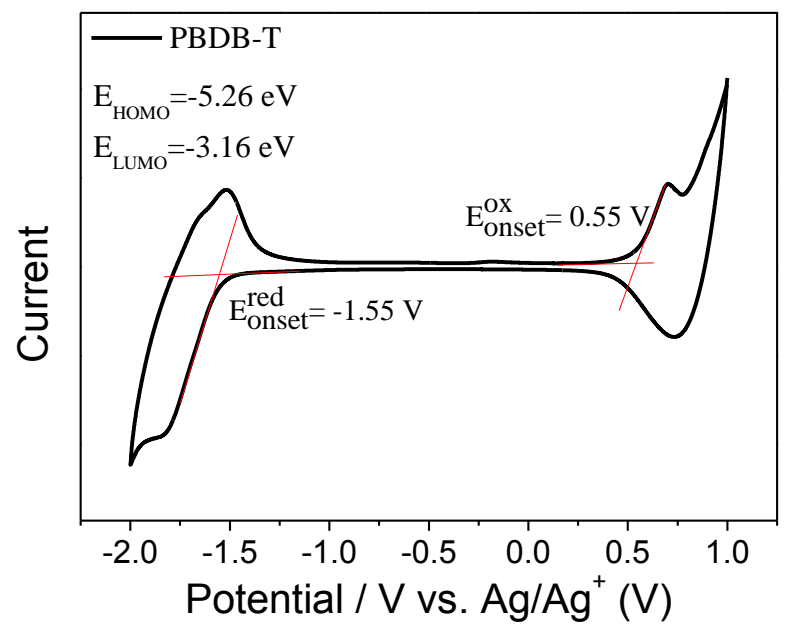

Figure S10. CV plot of PBDB-T film. 

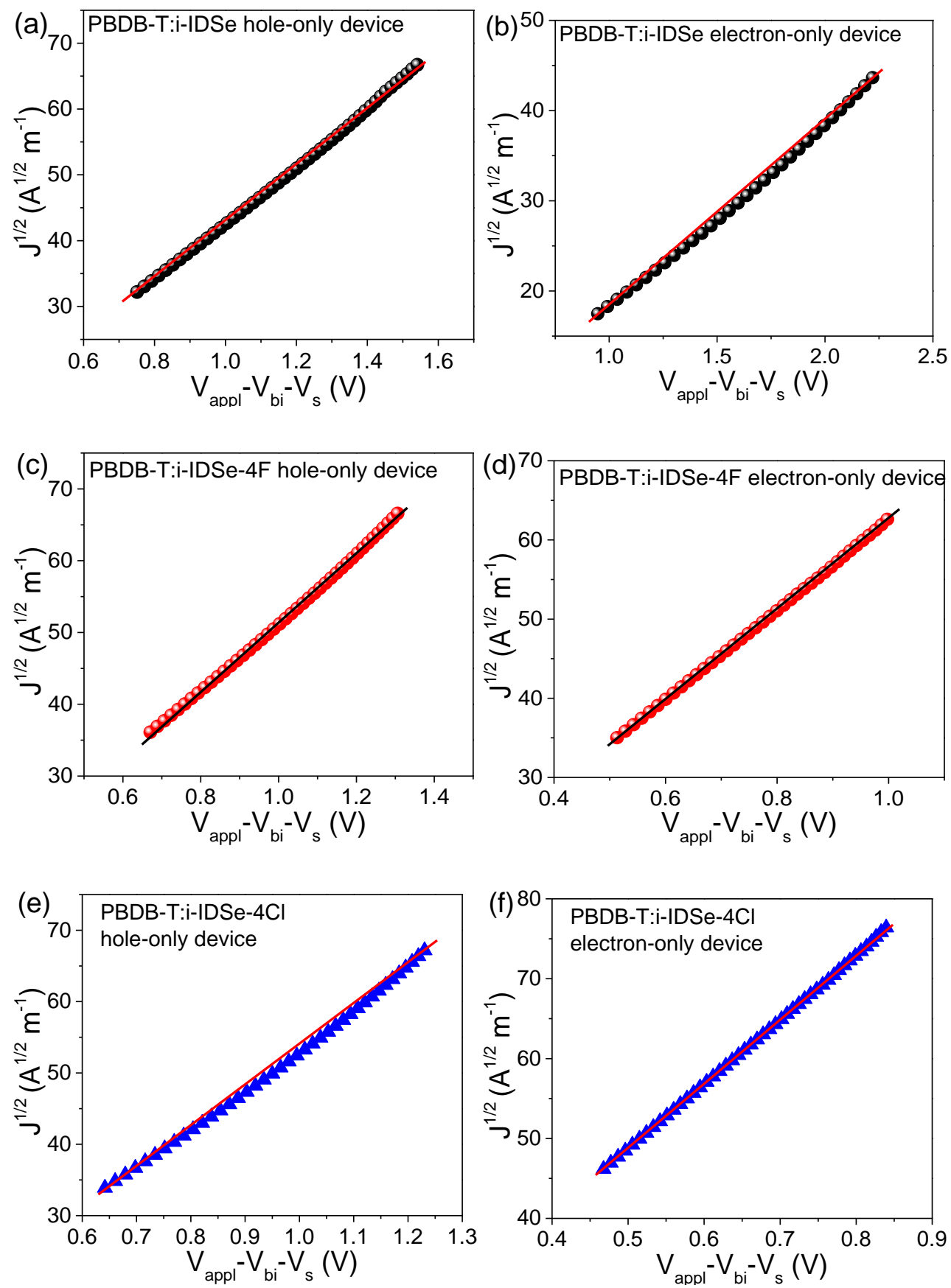

Figure S11. $J^{1 / 2} v s V$ plots: PBDB-T:i-IDSe hole-only diode (a) and electron-only diode (b); $J^{1 / 2} v s V$ plots:

PBDB-T:i-IDSe-4F hole-only diode (c) and electron-only diode (d); $J^{1 / 2} v s V$ plots: PBDB-T:i-IDSe-4CI hole-only diode (e) and electron-only diode (f). 

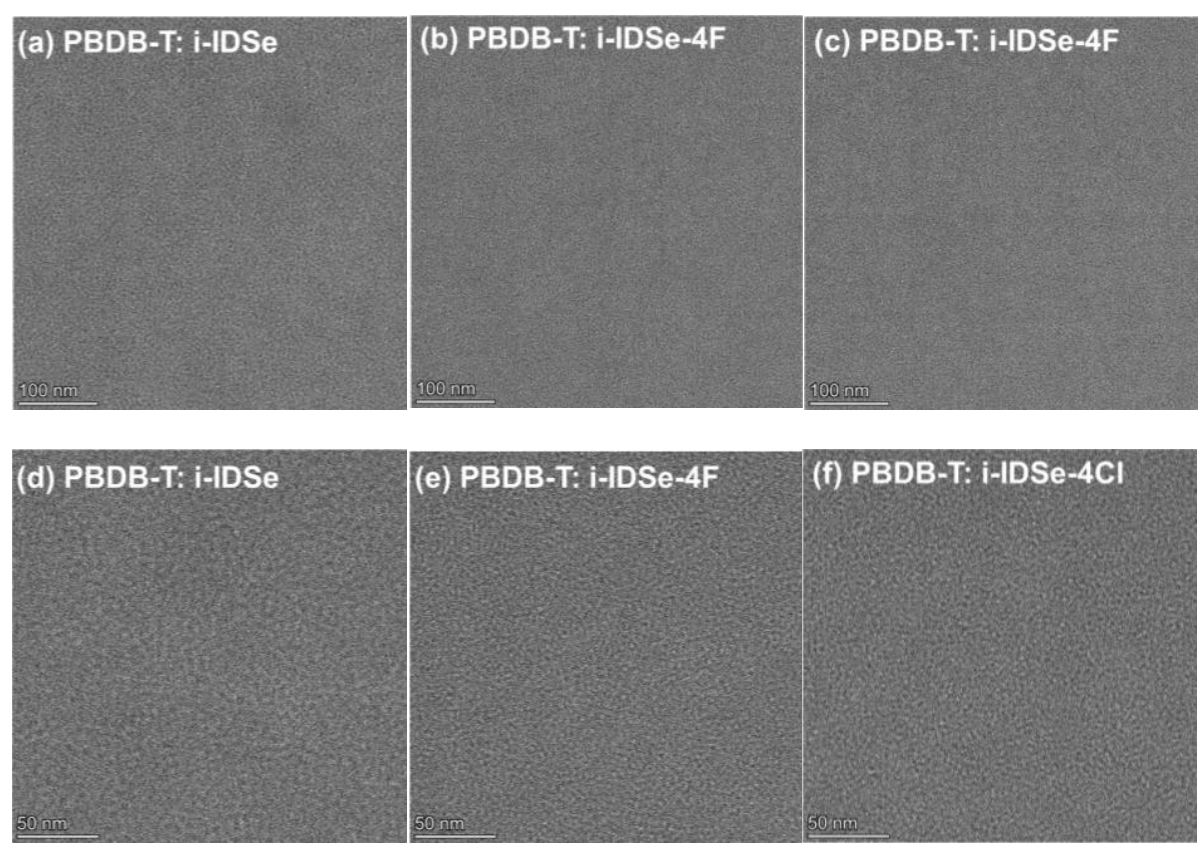

Figure S12. TEM images of the three blends with scale bar of $100 \mathrm{~nm}(\mathrm{a}, \mathrm{b}$, and $\mathrm{c})$ and $50 \mathrm{~nm}(\mathrm{~d}, \mathrm{e}$, and f).
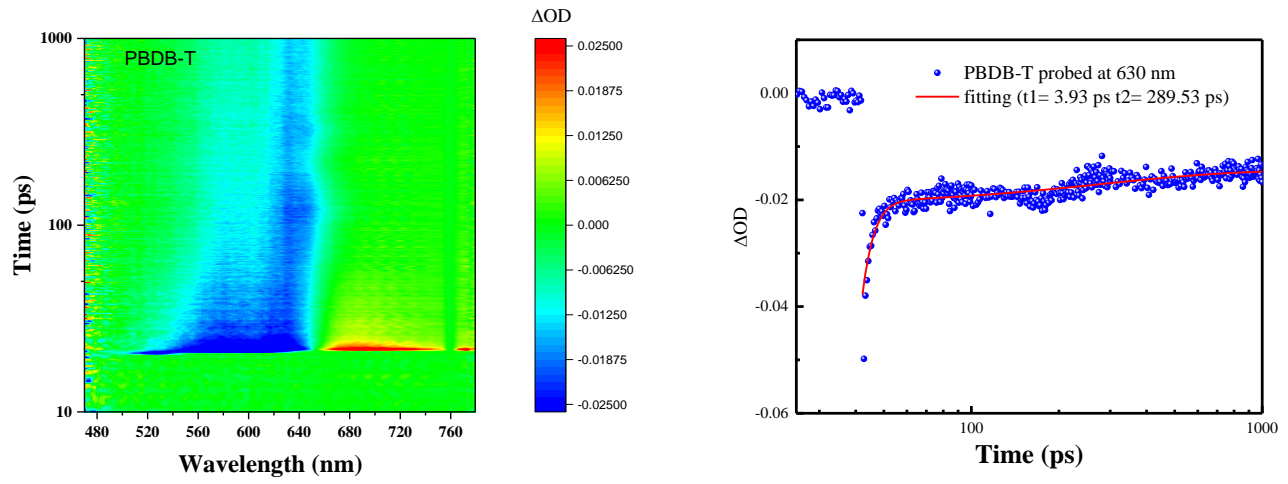

Figure S13. PBDT-T film@630nm t1=3.93ps t2=289.53ps
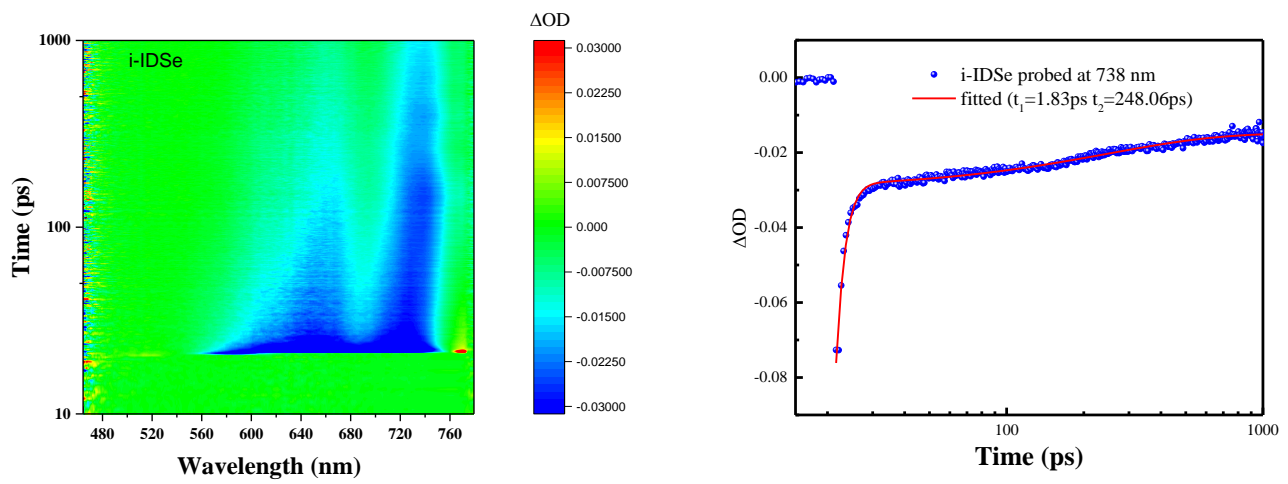

Figure S14.i-IDSe film@738nm t1=1.836ps t2=248.06ps 

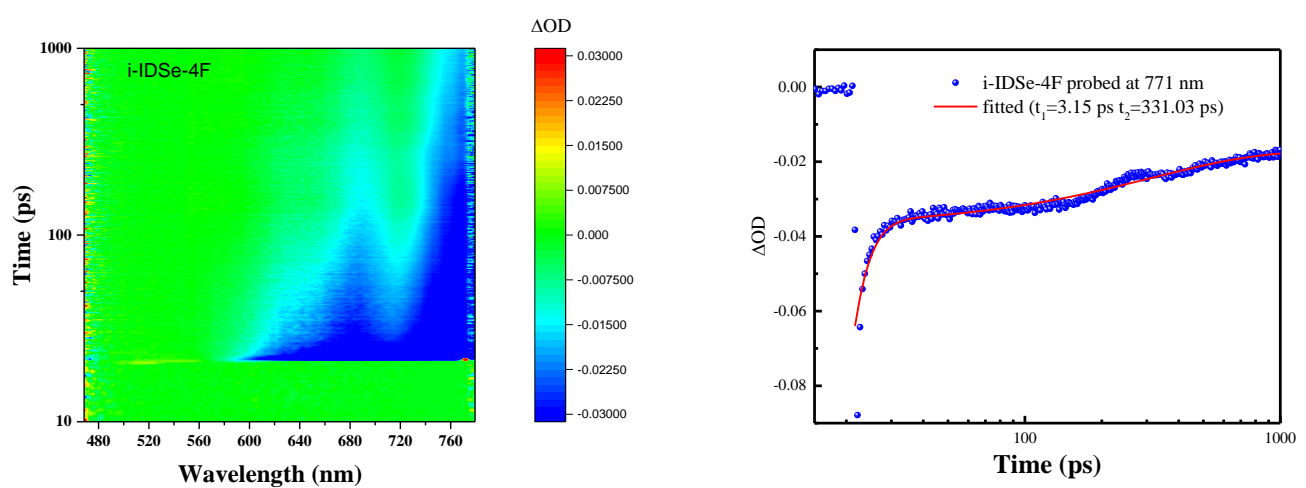

Figure S15. i-IDSe-4F film@ $938 \mathrm{~nm} \mathrm{t} 1=311.03 \mathrm{ps} \mathrm{t} 2=3.15 \mathrm{ps}$
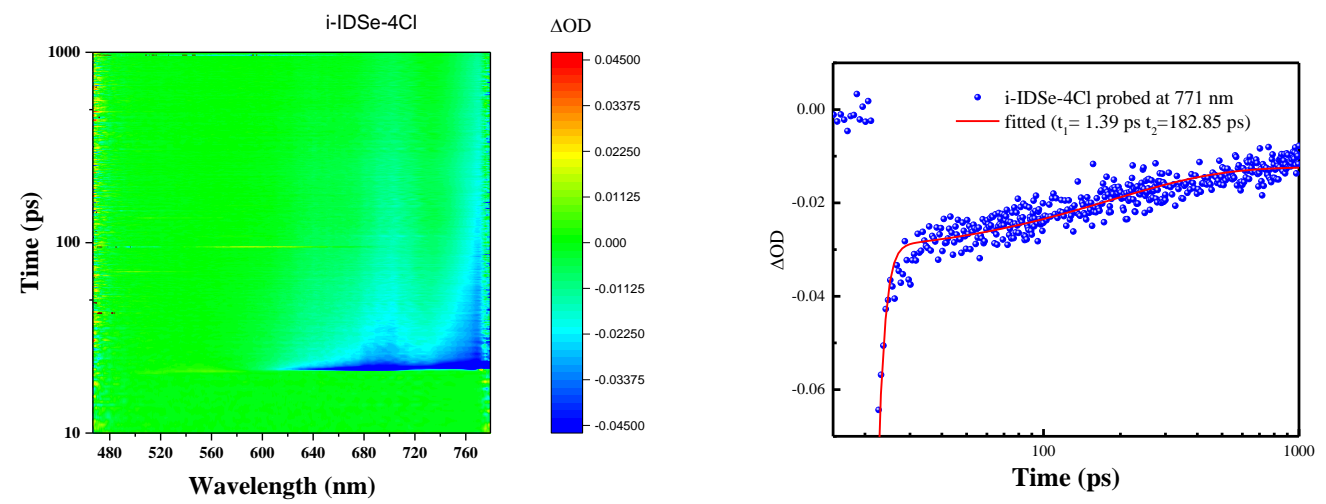

Figure S16. i-IDSe-4Cl film @ 738nm t $1=182.85 \mathrm{ps} \mathrm{t} 2=1.39 \mathrm{ps}$ 
Table S1. Calculations of total energy and their geometries of i-IDSe, i-IDSe-4F, and i-IDSe-4CI.

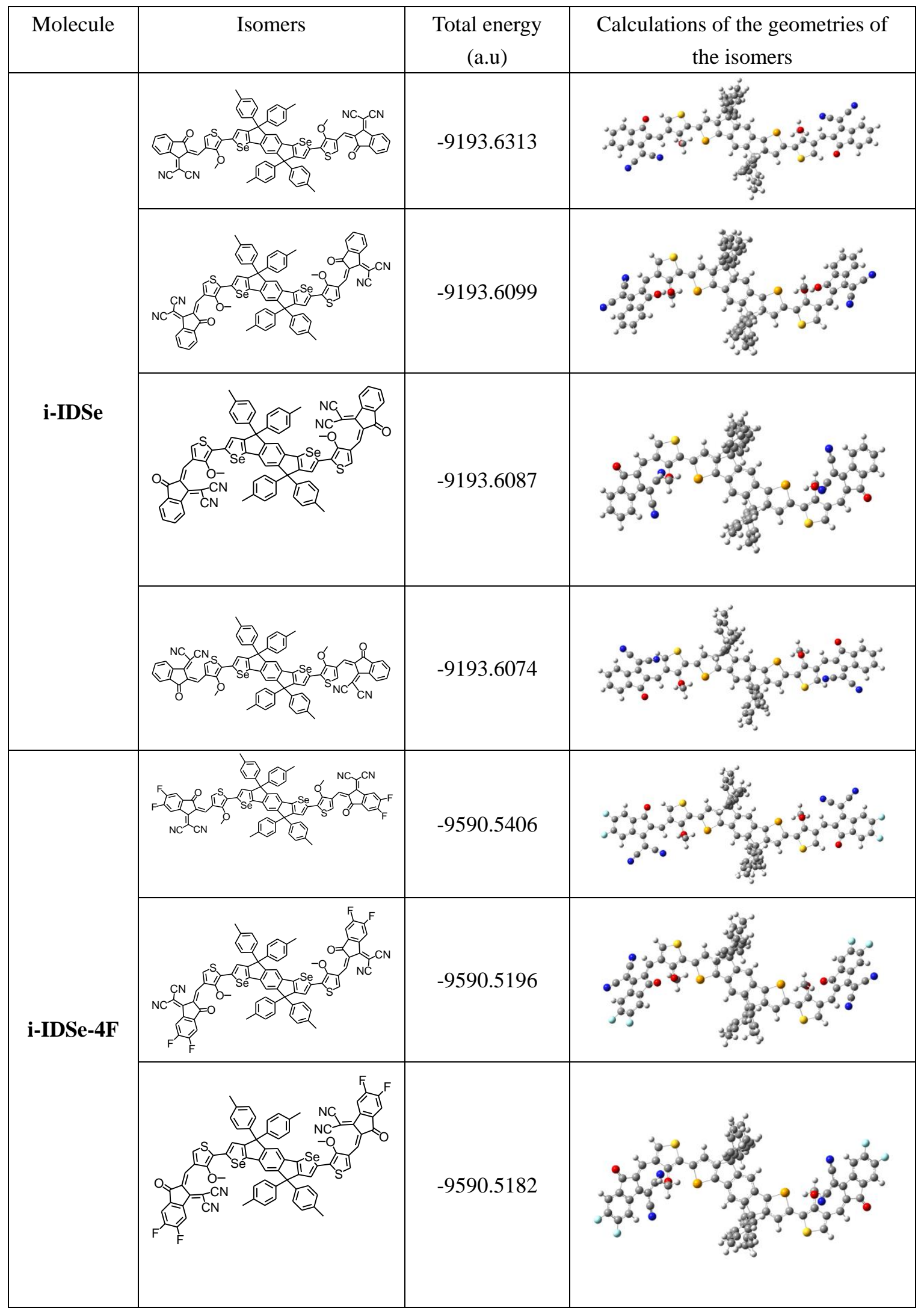




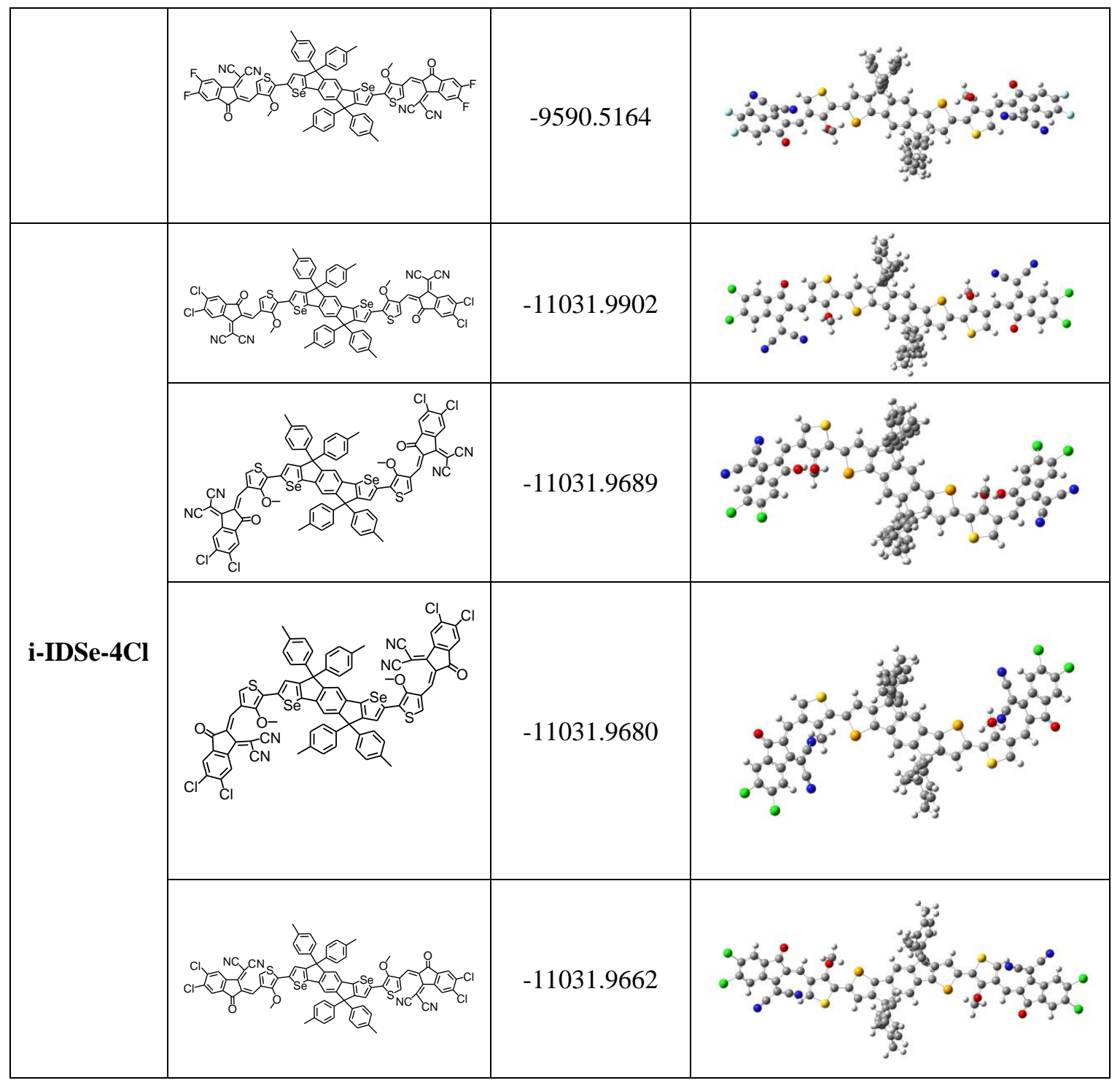

Table S2. Calculated molecular energy levels of i-IDSe, $\mathbf{i}-\mathbf{I D S e}-\mathbf{4 F}$, and $\mathbf{i}$-IDSe-4Cl at their optimized geometry.

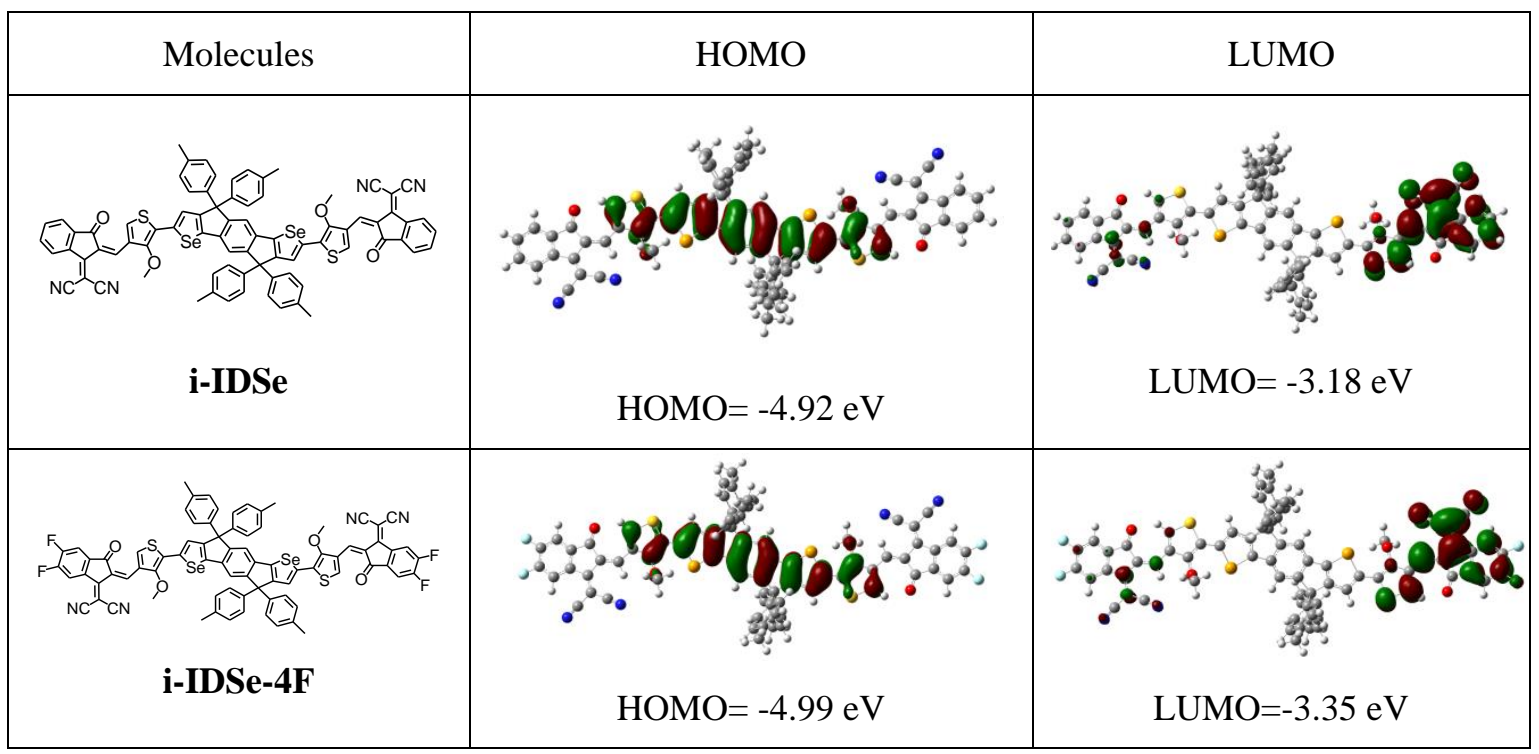




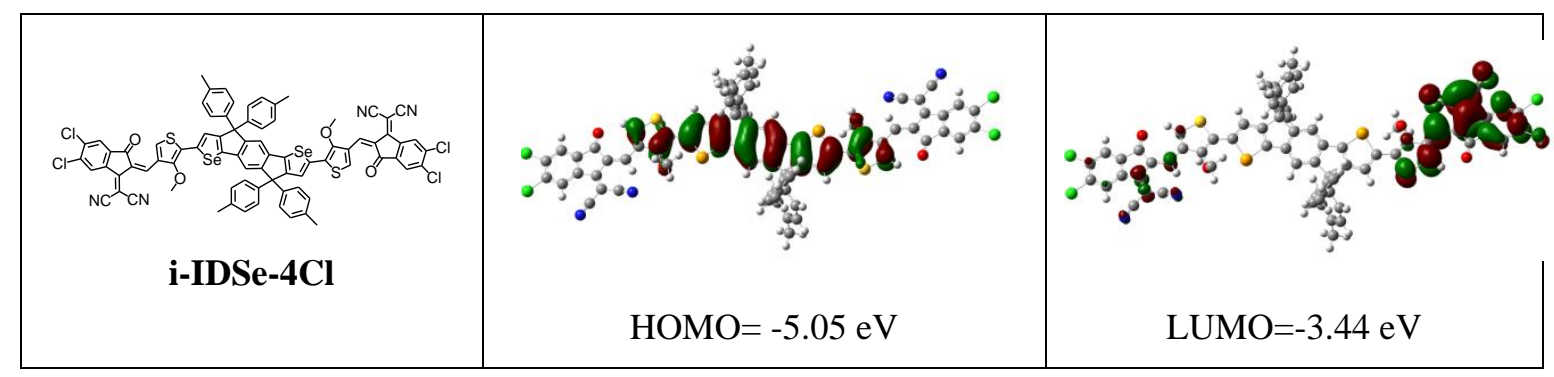

Table S3. Measurement of the hole and electron mobilities.

\begin{tabular}{|c|c|c|c|c|}
\hline Active layer & $\begin{array}{c}\text { Thickness } \\
(\mathrm{nm})\end{array}$ & $\begin{array}{c}\mu_{h} \\
\left(\mathrm{~cm}^{2} \mathrm{~V}^{-1} \mathrm{~s}^{-1}\right)\end{array}$ & $\begin{array}{c}\mu_{e} \\
\left(\mathrm{~cm}^{2} \mathrm{~V}^{-1} \mathrm{~s}^{-1}\right)\end{array}$ & $\mu_{h} / \mu_{e}$ \\
\hline PBDB-T:i-IDSe & 75 & $2.68 \times 10^{-4}$ & $5.93 \times 10^{-5}$ & 4.52 \\
\hline PBDB-T:i-IDSe-4F & 69 & $2.50 \times 10^{-4}$ & $3.52 \times 10^{-4}$ & 0.71 \\
\hline PBDB-T:i-IDSe-4Cl & 67 & $3.17 \times 10^{-4}$ & $6.54 \times 10^{-4}$ & 0.48 \\
\hline
\end{tabular}

\section{References}

1. Qian, D.; Ye, L.; Zhang, M.; Liang, Y.; Li, L.; Huang, Y.; Guo, X.; Zhang, S.; Tan, Z.; Hou, J. Design, Application, and Morphology Study of a New Photovoltaic Polymer with Strong Aggregation in Solution State. Macromolecules. 2012, 45, 9611-9617.

2. Intemann, J. J.; Yao, K.; Yip, H.-L.; Xu,Y.-X.; Li, Y.-X.; Liang, P.-W.; Ding,F.-Z.; Li, X.; Jen, A. K.-Y. Molecular Weight Effect on the Absorption, Charge Carrier Mobility, and Photovoltaic Performance of an Indacenodiselenophene-Based Ladder-Type Polymer. Chem. Mater. 2013, 25, 3188-3195.

3. Wang, W.; Zhao, B.; Cong, Z.; Xie, Y.; Wu, H.; Liang, Q.; Liu, S.; Liu, F.; Gao, C.; Wu, H.; Cao, Y. Nonfullerene Polymer Solar Cells Based on a Main-Chain Twisted Low-Bandgap Acceptor with Power Conversion Efficiency of 13.2\%. ACS Energy Lett. 2018, 3, 1499-1507.

4. Zhang, M.; Wang, J.; Zhang, F.; Mi, Y.; An, Q.; Wang, W.; Ma, X.; Zhang, J.; Liu, X. Ternary Small Molecule Solar Cells Exhibiting Power Conversion Efficiency of 10.3\%. Nano Energy. 2017, 39, 571-581. 